BMJ Nutrition, Prevention \& Health

\section{addressing barriers to healthy diet among low-income individuals at an urban, safety-net hospital}

\author{
Erin Cahill, ${ }^{1}$ Stacie R Schmidt, ${ }^{2}$ Tracey L Henry, ${ }^{2}$ Gayathri Kumar (D) , ${ }^{3}$ \\ Sara Berney, ${ }^{4}$ Jada Bussey-Jones, ${ }^{2}$ Amy Webb Girard ${ }^{1}$
}

To cite: Cahill E, Schmidt SR, Henry TL, et al. Qualitative research study on addressing barriers to healthy diet among low-income individuals at an urban, safety-net hospital. BMJ Nutrition, Prevention \& Health 2020;3:e000064. doi:10.1136/ bmjnph-2020-000064

- Additional material is published online only. To view please visit the journal online (http://dx.doi.org/10.1136/ bmjnph-2020-000064).

${ }^{1}$ Emory University School of Public Health, Atlanta, Georgia USA

${ }^{2}$ Division of General Medicine and Geriatrics, Emory University School of Medicine, Atlanta,

Georgia, USA

${ }^{3}$ Emory University School of Medicine, Atlanta, Georgia, USA ${ }^{4}$ North Carolina State University School of Public and International Affairs, Raleigh, North Carolina, USA

Correspondence to Tracey L Henry, General Medicine and Geriatrics, Emory University, Atlanta, GA 30322 , USA; henrytracey@hotmail.com

Received 13 January 2020 Revised 27 April 2020 Accepted 28 April 2020 Published Online First 9 September 2020

Check for updates

(c) Author(s) (or their employer(s)) 2020. Re-use permitted under CC BY-NC. No commercial re-use. See rights and permissions. Published by BMJ.

\section{ABSTRACT}

Background Some American households experience food insecurity, where access to adequate food is limited by lack of money and other resources. As such, we implemented a free 6-month Fruit and Vegetable Prescription Program within a large urban safety-net hospital .

Methods 32 participants completed a baseline and postintervention qualitative evaluation about food-related behaviour 6 months after study completion. Deductive codes were developed based on the key topics addressed in the interviews; inductive codes were identified from analytically reading the transcripts. Transcripts were coded in MAXQDA V.12 (Release 12.3.2).

Results The information collected in the qualitative interviews highlights the many factors that affect dietary habits, including the environmental and individual influences that play a role in food choices people make. Participants expressed very positive sentiments overall about their programme participation.

Conclusions A multifaceted intervention that targets individual behaviour change, enhances nutritional knowledge and skills, and reduces socioeconomic barriers to accessing fresh produce may enhance participant knowledge and self-efficacy around healthy eating. However, socioeconomic factors remain as continual barriers to sustaining healthy eating over the long term. Ongoing efforts that address social determinants of health may be necessary to promote sustainability of behaviour change.

\section{INTRODUCTION}

Most US households have consistent, reliable access to enough food for active, healthy living. ${ }^{1}$ Some American households, however, experience food insecurity, which is defined by the US Department of Agriculture (USDA) as a lack of consistent access to enough food for an active, healthy life. ${ }^{1}$ In 2016, an estimated one in eight Americans were food insecure, equating to 42 million people. ${ }^{1}$ Food insecurity can be influenced by a number of factors including income, employment and disability (Healthy People
2020). The prevalence of food insecurity varies across subgroups of the US population; some groups are more likely to be food insecure than others. The distribution of food insecurity across residence areas shows that the majority of food-insecure households are in metropolitan areas, with income as one of the primary characteristics associated with food insecurity. ${ }^{2}$ Lower income households have a higher prevalence of food insecurity compared with higher income households. ${ }^{2}$ Furthermore, food insecurity may increase the risk for obesity and chronic diseases. ${ }^{3}$

Food assistance programmes such as the Women, Infants and Children programme and the Supplemental Nutrition Assistance Program (SNAP) help address barriers to accessing healthy food and may reduce food insecurity. ${ }^{4} 5$ Interventions implemented within healthcare settings-such as onsite food pantries and mobile food distributions-that serve food-insecure populations have also been effective. ${ }^{3}$

Our hospital is a large, urban safety-net hospital in metro Atlanta that provides care to low income and other vulnerable populations. In 2015, an assessment of food insecurity was conducted in the hospital's primary care centre, where 323 patients completed a questionnaire that included questions regarding age, sex, race, household income, number of people in the household, zip code, diabetes status, the USDA two-item food security screener and SNAP utilisation. The study revealed that $55 \%$ of low-income patients receiving outpatient care were food-insecure. ${ }^{6}$ To address this issue, we implemented a free 6-month Fruit and Vegetable Prescription Program (FVRx) within a primary care clinic at the hospital in 2016.

Eligible participants had a Body Mass Index (BMI) $>30$ and at least one associated 
chronic condition, such as diabetes. Components of the FVRx programme included 4 weeks of fruit and vegetable prescriptions to be redeemed for fresh fruits and vegetables packaged locally, monthly interactive groups classes on nutrition, and monthly cooking classes providing evidence-based nutrition and cooking skills education.

On completion of the programme, we conducted a postintervention qualitative evaluation among participants of the FVRx programme to assess (1) constraints on programme participation, (2) barriers to maintaining a healthy diet among participants, (3) participant capacity to sustain behaviour change during and after completion of the programme, in an effort to identify strategies that could improve participant retention and satisfaction with future programmes. This paper describes the results of this evaluation.

\section{METHODS}

This evaluation incorporated a qualitative research study design. A telephone interview script was used to ask questions about patients' experience with the FVRx programme, grocery shopping habits and the patient's current fruit and vegetable consumption (see online supplementary appendix A). Interview questions were developed to address the main goals of the evaluation, which were to investigate constraints on programme participation, barriers to maintaining a healthy diet among participants postintervention and strategies to improve participant retention.

Enrolment of the 32 patients into the FVRx study occurred in June 2016; participation in the FVRx programme by the 32 participants took place from July 2016 to December 2016. Participants were referred to the programme by their primary care provider if they had a BMI $>30$ and at least one diet-related illness. All 32 participants had access to a phone rather their own or a family member's phone.

The first author contacted the original 32 patients who participated in the FVRx programme by phone in June 2017, approximately 6 months after completing the programme. Six of 32 participants did not answer but had a working voicemail, for which a maximum of two messages were left. Additionally, the team encountered the wrong number for three participants, and full mailboxes for two numbers. Two numbers went unanswered (no voicemail) and one number was disconnected. Thus, of the 32 participants, 18 were reached by phone and verbally consented to participate in follow-up evaluation. Seven participants completed the programme while 11 participants attended a few classes but dropped out. None of the FVRx participants contacted refused to be interviewed.

Interviews were recorded using the TapeACall app and transcribed verbatim. Four interviews were not recorded due to technical difficulties with the app. In these instances, detailed notes were taken and were used in analyses in lieu of verbatim transcripts. A codebook

\begin{tabular}{|c|c|}
\hline $\begin{array}{l}32 \text { FVRx } \\
\text { participants }\end{array}$ & $\begin{array}{l}\text { Percentages based on baseline } \\
\text { survey responses }\end{array}$ \\
\hline Sex & $72 \%$ women \\
\hline Race & $\begin{array}{l}90.6 \% \text { Black/African or Caribbean } \\
\text { American }\end{array}$ \\
\hline Employment status & $\begin{array}{l}68.8 \% \text { unemployed, homemakers or } \\
\text { on disability }\end{array}$ \\
\hline Household income & $81.3 \%$ with annual income $<\$ 25000$ \\
\hline \multirow[t]{2}{*}{ Insurance status } & $28.1 \%$ uninsured \\
\hline & $\begin{array}{l}53.1 \% \text { insured through medicaid or } \\
\text { other public insurance }\end{array}$ \\
\hline SNAP enrolment & $43.8 \%$ receiving SNAP benefits \\
\hline Food security & $56.3 \%$ low or very low food security \\
\hline
\end{tabular}

*Source: FVRx 2016 Fruit and Vegetable Prescription Program Report.

SNAP, Supplemental Nutrition Assistance Program.

was developed consisting of deductive and inductive codes. Deductive codes were developed based on the key topics addressed in the interviews; inductive codes were identified from analytically reading the transcripts. Transcripts were uploaded to and coded in MAXQDA V.12 (Release 12.3.2). Constant comparative analysis was used to compare experiences and perspectives between those who graduated and those who dropped out. This comparison was undertaken to understand how capabilities, motivations and opportunities changed over the course of their participation, and how this ultimately influenced programme retention.

\section{RESULTS}

Participant data on demographic and socioeconomic characteristics were collected at baseline (table 1).

\section{Overall participant perspectives of the program}

When asked about their main motivation for enrolling in the programme, most participants reported the desire to eat healthier and the desire to lose weight. 'Motivation to enrol' was one of the codes used in MAXQDA for the analysis, with subcodes of lose weight, eat healthy or doctor recommended. Of the 18 people interviewed, 8 or $44 \%$ mentioned enrolling in the programme to lose weight, and 11 or $61 \%$ mentioned enrolling to learn to eat healthy. When asked about the most useful thing they learnt in the programme, nearly all the respondents mentioned an improvement in their knowledge of nutrition, such as learning correct portion sizes or reading nutrition labels. Other participants reported enjoying meeting new people and having a sense of camaraderie and support from the group. Additionally, over half of 
the participants, including those who did not finish the classes, said they would like to enrol in the programme again if given the opportunity.

\section{Participant capacity to sustain behaviour change}

When asked about fruit and vegetable consumption since the programme ended, most respondents reported they continue to eat a good amount of fruits and vegetables (Excerpts: 'I'm beginning to start to like broccoli and been doing some kale' and 'Yes, I do a lot of salads and fruits...I am loving the fresh fruits'). The majority of participants reported that they continue to use the lessons they learnt in the healthy living and cooking classes when making food choices.

Of the 18,15 or $83 \%$ respondents mentioned nutrition knowledge as a positive takeaway from the programme, and 15 of the 18 or $83 \%$ respondents also mentioned continuing to consume fruits and vegetables.

\section{Constraints on program participation}

Two participants mentioned that even though they were getting free food with the vouchers, it was still expensive (Excerpt: 'I had to pay a co-pay each time, and it just got too expensive...'). Others reported challenges in having transportation to attend the Healthy Living Classes (Excerpt: 'I wasn't able at that time to have the transportation to go to all of them'). Another participant with mobility limitations had difficulty picking up their packaged fresh produce. Those who did not graduate cited their own or a family member's poor health; out of pocket costs (ie, copays); lack of affordable transportation or parking; and/or inconvenient scheduling of the sessions. 'Dropout/Missed Sessions Reasons' code had a subcode of transportation/mobility, and four of the 18 or $22 \%$ of the respondents mentioned lack of transportation as their reason for not attending classes.

\section{Barriers to maintaining a healthy diet among participants}

When asked what they believe the biggest barrier to healthy eating is, the most commonly reported answer was cost $(\mathrm{n}=6)$ (Excerpt: '...for people like me, that have so many medical bills...it's easier to get the cheaper, unhealthy things...'). Another participant explained that her family often gets groceries from the food pantry, where the healthy options such as fresh produce are limited. Another reported barrier was finding the time to cook healthy meals, especially when working or caring for children. Over half of the respondents mentioned shopping at multiple stores in order to obtain the lowest prices (Excerpt: 'I shop at the cheapest store I can get it (fruits and vegetables) at').

\section{DISCUSSION}

This evaluation reveals that most participants of the FVRx programme reported improved knowledge of nutrition and continue to consume fresh fruits and vegetables months after completion of the programme. However,
FVRx participants continue to encounter barriers to maintaining a healthy diet with the most commonly reported barriers being the cost of fresh produce and competing priorities such as child care which prohibited time dedicated to healthy food preparation.

Lifestyle change interventions have been shown to be effective in the treatment and prevention of diet-related illnesses such as diabetes. ${ }^{7}$ Similarly, other research has shown the use of goal setting and small groups to be promising tools in dietary behaviour modification, both of which are used in FVRx. ${ }^{8}$ However, lifestyle change initiatives and health education may be ineffective in increasing healthy food consumption if they do not take into consideration other factors such as neighbourhood segregation, market strategies and poverty as important modifiers of accessibility. ${ }^{9}$ In order to address the food insecurity in these low-income patients, we have to find ways to tackle the cost barriers they face when it comes to accessing healthier foods. Our FVRx programme attempts to integrate both health education and monetary incentives through vouchers, enabling improvement in participant knowledge of healthy eating and addressing any socioeconomic barriers to eating fresh fruits and vegetables during the intervention.

Without access to free fruits and vegetables through vouchers, consumption of fruits and vegetables continued to be met with challenges such as their cost and competing priorities that precluded time for healthy food preparation. This highlights the importance of incorporating strategies that equip participants with the knowledge and self-efficacy to continue healthy behaviours, even after the programme has ended. While the healthy living curriculum and cooking classes work to provide participants with those tools, conducting follow-up with participants at various intervals, via phone calls or hosting alumni events to serve as booster sessions, could be useful strategies to increase likelihood of continued behaviour.

There are a few limitations to this study. One limitation is that qualitative data were collected from a small sample of participants of the programme. However, this study was intended to be an evaluation of a pilot programme, and results will be used to inform expansion of the FVRx programme within our hospital.

Given the poverty status of many of our patients (figure 1 ), it is expected that many would have transient housing, possibly leading to the wrong number for three participants, and a disconnected telephone numbers for one another participant. Such social determinants might have also affected the ability to afford transportation to and from classes, as well as copays for the classes. We suspect these factors contributed to the high dropout rate $(n=11)$ and the $44 \%$ non-response rate when calling patients 6 months postcompletion of the programme. This is potentially supported by our findings among the six respondents who mentioned cost as the biggest barrier; five of those were individuals who did not finish the programme. The interviews show that nearly all 18 of the respondents had the same motivation for starting the programme: to 
learn to eat better; however for those that did not 'graduate' $(n=11)$, they reported current life circumstances as preventing them from completing the programme. This included health issues (their own or that of a family member), scheduling or difficulty with transportation to the programme site were reported by respondents as reasons for dropping out. These types of variables are not able to be addressed through the FVRx programming in the pilot phase of the programme, but should be researched and addressed in larger studies moving forward

\section{CONCLUSION}

Our multifaceted FVRx pilot programme enhanced participants' nutritional knowledge and skills and continued consumption of fresh produce months after completion of the programme. However, socioeconomic factors remain as continual barriers to sustaining healthy eating. Additional efforts may be necessary to promote sustained healthy eating, such as skill building around gardening and growing fresh produce in the home. Using these types of innovative approaches may empower lower income populations to overcome barriers to healthy behaviour change. Efforts to improve participant retention in the programme, expand the programme to more participants and promote sustained behaviour change on programme completion are underway.

Acknowledgements We would like to acknowledge Wholesome Wave Georgia, Project Open Hand, and The Common Market for their contributions to the FVRx program at our site. We are appreciative to Grady Memorial Hospital and the Primary Care Center for their innovative role in implementing systems change by supporting patient-centred group classes and FVRx prescriptions at our site.

Contributors All authors listed have contributed sufficiently to the project to be included as authors, and all those who are qualified to be authors are listed in the author byline. Authors' contributions: EC conducted the study and the analysis for the study, and helped to write up the study. SRS (MD) gave idea for study and helped plan and conduct the study and helped write up the study. TLH (MD, MPH, MS, FACP) helped plan, developed and conducted the study along with helping write up the study. SB helped plan, developed and conducted the study along with helping to write up the study. GK (MD) helped plan the study and write up the study. JB-J (MD, FACP) helped plan and developed the study. AWG (PhD) supervised and assisted EC in conducting the study and analysing the study and helped to write up the study.
Funding The authors have not declared a specific grant for this research from any funding agency in the public, commercial or not-for-profit sectors.

Competing interests None declared.

Patient consent for publication Not required.

Ethics approval All study protocols, informed consent documents and tools were reviewed and approved by the hospital review board and deemed exempt from review by Emory University Institutional Review Board. All participants gave verbal informed consent to participate and provided permission to record the call.

Provenance and peer review Not commissioned; externally peer reviewed.

Open access This is an open access article distributed in accordance with the Creative Commons Attribution Non Commercial (CC BY-NC 4.0) license, which permits others to distribute, remix, adapt, build upon this work non-commercially, and license their derivative works on different terms, provided the original work is properly cited, appropriate credit is given, any changes made indicated, and the use is non-commercial. See: http://creativecommons.org/licenses/by-nc/4.0/.

ORCID iD

Gayathri Kumar http://orcid.org/0000-0002-2791-9960

\section{REFERENCES}

1 Coleman-Jensen A, Rabbitt MP, Gregory CA, et al. Household food security in the United States in 2016. U.S. department of agriculture economic research report 2017:237.

2 Rabbitt M, Coleman-Jensen A, Gregory C. Understanding the prevalence, severity, and distribution of food insecurity in the United States. amber waves, economic research service, USDA, 2017. Available: https://www.ers.usda.gov/amber-waves/2017/september/ understanding-the-prevalence-severity-and-distribution-of-foodinsecurity-in-the-united-states/ [Accessed 16 Feb 2018].

3 Mook K, Laraia BA, Oddo VM, et al. Food security status and barriers to fruit and vegetable consumption in two Economically deprived communities of Oakland, California, 2013-2014. Prev Chronic Dis 2016;13:E21.

4 Kreider B, Pepper JV, Roy M. Identifying the effects of WIC on food insecurity among infants and children. Lexington: University of Kentucky Center for Poverty Research, 2012.

5 Ratcliffe C, McKernan S-M, Zhang S. How much does the supplemental nutrition assistance program reduce food insecurity? Am J Agric Econ 2011;93:1082-98.

6 Girovich B. Hunger is Health: The Association Between Food Insecurity and Diabetes in the Primary Care Center (PCC) at Grady Hospital in Atlanta, GA. Master's of Public Health Thesis. Emory University, Rollins School of Public Health, 2015. http://pid.emory.edu/ ark:/25593/s0s 19

7 Knowler WC, Barrett-Connor E, Fowler SE, et al. Reduction in the incidence of type 2 diabetes with lifestyle intervention or metformin. $N$ Engl J Med 2002;346:393-403.

8 Ammerman AS, Lindquist CH, Lohr KN, et al. The efficacy of behavioral interventions to modify dietary fat and fruit and vegetable intake: a review of the evidence. Prev Med 2002;35:25-41.

9 Azétsop J, Joy TR. Access to nutritious food, socioeconomic individualism and public health ethics in the USA: a common good approach. Philos Ethics Humanit Med 2013;8:16. 